OP0166 RADIOGRAPHIC OUTCOMES FROM A RANDOMIZED, DOUBLE-BLIND, PLACEBO-CONTROLLED, PHASE 2 STUDY OF A NOVEL, INTRA-ARTICULAR, INJECTABLE, WNT PATHWAY INHIBITOR (SM04690) IN THE TREATMENT OF OSTEOARTHRITIS OF THE KNEE: WEEK 26 INTERIM ANALYSIS

Y. Yazici ${ }^{1}$, T.E. McAlindon ${ }^{2}$, A. Gibofsky ${ }^{3}$, N.E. Lane ${ }^{4}$, N. Skrepnik ${ }^{5}$, E. Armas ${ }^{6}$, C.J. Swearingen ${ }^{1}$, A. DiFrancesco ${ }^{1}$, J.R. Tambiah ${ }^{1}$, M.C. Hochberg ${ }^{7}$. ${ }^{1}$ Samumed, LLC, San Diego, CA; ${ }^{2}$ Tufts Medical Center, Boston, MA; ${ }^{3}$ Weill Cornell Medical College and Hospital for Special Surgery, New York, NY; ${ }^{4} U C$ Davis Medical Center, Davis, CA; ${ }^{5}$ Tucson Orthopedic Institute, Tucson, AZ; ${ }^{6}$ Well Pharma, Miami, FL; ${ }^{7}$ University of Maryland School of Medicine, Baltimore, MD, United States

Background: Knee osteoarthritis $(\mathrm{OA})$ is characterized by pain, functional impairment, and joint space narrowing due to degradation of articular cartilage and bone remodeling. The Wnt pathway plays a central role in the formation of joint tissues, and altered Wnt signaling has been associated with cartilage loss in preclinical studies. SM04690 is a small molecule Wnt pathway inhibitor in development as a disease modifying OA drug (DMOAD) and administered as an intra-articular (IA) knee injection. A phase 2, multicenter, 52-week, single-dose, randomized controlled trial of SM04690 is ongoing in subjects with moderate to severe knee OA. Radiographic results from an interim analysis at 26 weeks are reported.

Objectives: To evaluate the safety and efficacy of SM04690 IA injection for the treatment of $\mathrm{OA}$.

Methods: Subjects were randomized to receive a single, $2 \mathrm{~mL}$, IA injection of 0.03 $\mathrm{mg}, 0.07 \mathrm{mg}, 0.23 \mathrm{mg} \mathrm{SM04690}$ or placebo into the target knee on Treatment Day 1 . Safety, tolerability and efficacy outcomes were assessed at Weeks 4, 13 and 26. Target knee radiographs were taken at baseline and Week 26; change in medial joint space width (mJSW) was analyzed using an intention-to-treat analysis of covariance (ANCOVA) adjusting for baseline mJSW.

Results: 455 subjects (average age $60.3[ \pm 8.7]$ years, 268 [58.9\%] female, mean BMI 29.9 [ \pm 4.6$] \mathrm{kg} / \mathrm{m}^{2}, 293$ [64.4\%] Kellgren-Lawrence Grade 3, 291 [64.0\%] bilateral OA) were enrolled. At Week 26, 8 serious adverse events (SAEs) in 7 subjects were reported; these were deemed unrelated to drug by the investigators. Mean $\mathrm{mJSW}$ change from baseline was $-0.22[ \pm 0.64] \mathrm{mm}$ in placebo cohort (table 1). Compared to placebo, mean mJSW change from baseline was $-0.07[ \pm 0.62]$ $\mathrm{mm}$ in the $0.03 \mathrm{mg}(p=0.069),-0.16[ \pm 0.95] \mathrm{mm}$ in $0.07 \mathrm{mg}(p=0.489)$, and -0.03 $[ \pm 0.59] \mathrm{mm}$ in $0.23 \mathrm{mg}(p=0.019)$ cohorts, respectively. Increase in mean mJSW was observed in $50(47.6 \%)$ subjects in $0.03 \mathrm{mg}, 45(40.5 \%)$ subjects in 0.07 $\mathrm{mg}, 40(39.6 \%)$ subjects in $0.23 \mathrm{mg}$ and $32(30.5 \%)$ subjects in placebo cohorts, respectively (figure 1). Odds of mJSW improvement, defined as change in mJSW $>0$, were increased $107 \%$ in $0.03 \mathrm{mg}$ cohort compared to placebo (OR=2.1, 95\% $\mathrm{Cl}[1.2,3.7], p=0.011)$, and odds of mJSW improvement were increased $69 \%$ for all SM04690 doses combined compared to placebo (OR=1.7, 95\% Cl [1.1, 2.7], $P=0.029)$. Additionally, in a priori subanalyses, each treatment cohort, and all SM04690 doses combined, had higher probability of improving mJSW in the unilateral OA subgroup, with a $420 \%$ increase in odds of JSW response compared to placebo (all SM04690 groups combined OR=5.2, 95\% Cl [2.1, 12.8], $p<0.001$ ).

\begin{tabular}{lccccc}
\multicolumn{7}{c}{ Table 1. Medial joint space width at baseline and week 26 } & & & \\
& $\mathbf{0 . 0 3} \mathbf{~ m g}$ & $\mathbf{0 . 0 7} \mathbf{~ m g}$ & $\mathbf{0 . 2 3} \mathbf{~ m g}$ & All SM04690 & Placebo \\
\hline $\mathbf{N}$ & 111 & 117 & 109 & 337 & 116 \\
Baseline (mm) [Mean (SD)] & $3.41(1.28)$ & $3.45(1.11)$ & $3.08(1.26)$ & $3.34(1.24)$ & $3.33(1.36)$ \\
Week 26 (mm) [Mean (SD)] & & & & & \\
Actual & $3.38(1.38)$ & $3.30(1.40)$ & $3.06(1.38)$ & $3.25(1.39)$ & $3.10(1.52)$ \\
Change from baseline & $-0.07(0.62)^{*}$ & $-0.16(0.95)$ & $-0.03(0.59)^{* *}$ & $-0.09(0.74)$ & $-0.22(0.64)$ \\
\hline
\end{tabular}

*0.03 mg vs $P B O, p=0.069 ;{ }^{* *} 0.23 \mathrm{mg}$ vs $\mathrm{PBO}, \mathrm{p}=0.019$

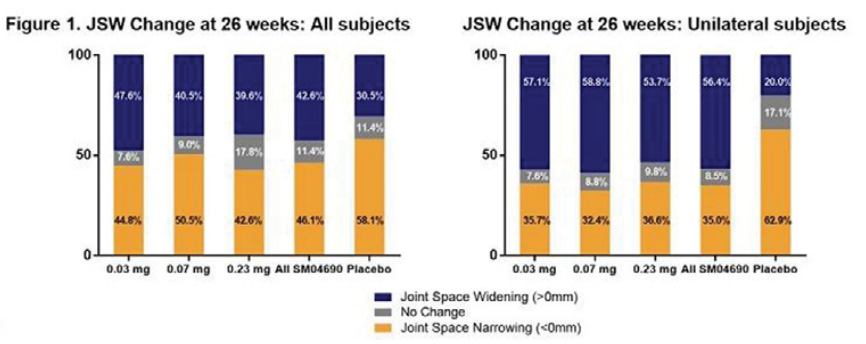

Conclusions: Radiographic outcomes from this interim analysis demonstrated that treatment with SM04690 maintained or increased JSW compared to placebo. These data support the continued development of SM04690 as a potential DMOAD for the treatment of knee OA. Further studies are ongoing.

Disclosure of Interest: Y. Yazici Shareholder of: Samumed, LLC, Employee of: Samumed, LLC, T. McAlindon Grant/research support from: Samumed, Consultant for: Astellas, Flexion, Pfizer, Regeneron, Samumed,and Seikugaku, A. Gibofsky Shareholder of: AbbVie, Amgen, J\&J, GSK, Regeneron, Consultant for: AbbVie, Pfizer, Horizon, Iroko, Celgene, Novartis/Sandoz, Samumed, Speakers bureau: AbbVie, Amgen, Celgene, Pfizer, N. Lane Consultant for: Samumed, LLC, N. Skrepnik Grant/research support from: Samumed, LLC, Consultant for: Orthofix and Sanofi, E. Armas Grant/research support from: Samumed, LLC,
C. Swearingen Shareholder of: Samumed, LLC, Employee of: Samumed, LLC, A. DiFrancesco Shareholder of: Samumed, LLC, Employee of: Samumed, LLC, J. Tambiah Shareholder of: Samumed, LLC, Employee of: Samumed, LLC, M. Hochberg Consultant for: Bioberica, EMD Serono, Novartis Pharma AG, Plexxicon, Pfizer, Proximagen, Regeneron, Samumed, and Theralogix LLC DOI: 10.1136/annrheumdis-2017-eular.3845

\section{OP0167 EFFICACY AND SAFETY OF CNTX-4975 IN SUBJECTS WITH MODERATE TO SEVERE OSTEOARTHRITIS KNEE PAIN: 24-WEEK, RANDOMIZED, DOUBLE-BLIND, PLACEBO-CONTROLLED, DOSE-RANGING STUDY}

R. Stevens ${ }^{1}$, D. Petersen ${ }^{2}$, J. Ervin ${ }^{3}$, J. Nezzer $^{4}$, Y. Nieves ${ }^{4}$, J. Campbell $^{1}$, K. Guedes ${ }^{1}$, R. Burges ${ }^{1}$, P. Hanson ${ }^{1}$. ${ }^{1}$ Centrexion Therapeutics, Boston; ${ }^{2}$ Noble Clinical Research, LLC, Tucson; ${ }^{3}$ The Center for Pharmaceutical Research, Kansas City; ${ }^{4}$ Premier Research, Durham, United States

Background: Osteoarthritis causes joint pain, stiffness, and reduced function, leading to disability. CNTX-4975, a highly purified, synthetic trans-capsaicin, targets the transient receptor potential vanilloid 1, producing analgesia via reversible deactivation of end terminals of primary afferent pain fibers within the joint and capsule.

Objectives: This 24-week dose-ranging study evaluated CNTX-4975 efficacy and safety in subjects with chronic, moderate to severe osteoarthritis-associated knee pain.

Methods: Subjects aged 45-80 years with chronic knee osteoarthritis, stable moderate to severe knee pain, and intolerability to oral or intra-articular analgesics were randomized to a single injection of placebo, CNTX-4975 $0.5 \mathrm{mg}$, or CNTX$49751.0 \mathrm{mg}$. The primary efficacy endpoint was the area under the curve (AUC) for change from baseline in daily Western Ontario and McMaster Universities Osteoarthritis Index (WOMAC) A1 score through week 12. Least squares mean differences (LSMD) for CNTX-4975 vs placebo were calculated for the primary endpoint and the average weekly AUC WOMAC A1 scores using analysis of covariance. Additional efficacy endpoints, mean change from baseline in weekly WOMAC A1 score, WOMAC B stiffness subscale, and WOMAC C physical function subscale through week 24, were analyzed using a mixed model for repeated measures (MMRM). Statistical tests were 2 -sided (alpha, $P=0.10$ ). Safety assessments included treatment-emergent adverse events (TEAEs).

Results: Efficacy was evaluated in 172 subjects (placebo, $n=69$; CNTX-4975 $0.5 \mathrm{mg}, \mathrm{n}=33$; CNTX-4975 $1.0 \mathrm{mg}, \mathrm{n}=70)$. Mean WOMAC A1 pain scores at baseline were 7.4 (placebo), 7.2 (CNTX-4975 $0.5 \mathrm{mg}$ ), and 7.2 (CNTX-4975 1.0 $\mathrm{mg}$ ). In the primary efficacy analysis, significant improvements vs placebo in WOMAC A1 scores were observed at week 12 with CNTX-4975 $0.5 \mathrm{mg}$ (LSMD: -0.8; $P=0.07$ ) and CTNX-4975 $1.0 \mathrm{mg}$ (LSMD: $-1.6 ; P<0.0001)$. Significant improvements vs placebo were also observed at week 24 with CNTX-4975 1.0 mg (LSMD: $-1.35 ; P=0.0002)$. In the MMRM analysis, significant improvements in WOMAC A1 scores vs placebo were demonstrated with CNTX-4975 $0.5 \mathrm{mg}$ at week 12 (LSMD: $-0.9 ; P=0.087$ ) but not week 24 (LSMD: $-0.5 ; P=0.41$ ), and with CNTX-4975 $1.0 \mathrm{mg}$ at weeks 12 (LSMD: $-1.5 ; P=0.0003$ ) and 24 (LSMD: $-0.9 ; P=0.067$ ). CNTX-4975 $1.0 \mathrm{mg}$ significantly improved WOMAC B (LSMD: $-2.5 ; P=0.0013)$ and WOMAC $C$ scores vs placebo (LSMD: $-18.3 ; P=0.004$ ) at week 12. Numerically greater improvements were observed in WOMAC B and $C$ at week 24, but differences were not significant (WOMAC B LSMD: -1.2 ; $P=0.14$; WOMAC C LSMD: $-7.2 ; P=0.28)$. In the safety population, the incidence of TEAEs was $30 \%$ for placebo or CNTX-4975 $1.0 \mathrm{mg}$, and $47 \%$ for CNTX-4975 $0.5 \mathrm{mg}$ at week 24. Most TEAEs were considered unrelated to study treatment. Arthralgia was the most common TEAE with CNTX-4975 $1.0 \mathrm{mg}$ (placebo, 5.7\%; CNTX-4975 $1.0 \mathrm{mg}, 7.0 \%$ ).

Conclusions: A single injection of CNTX-4975 $1.0 \mathrm{mg}$ improved pain with walking, knee stiffness, and physical function, and was well tolerated in subjects with moderate to severe osteoarthritis-associated knee pain

Disclosure of Interest: R. Stevens Shareholder of: Centrexion Therapeutics, Employee of: Centrexion Therapeutics, D. Petersen: None declared, J. Ervin: None declared, J. Nezzer Consultant for: Centrexion Therapeutics, Y. Nieves Consultant for: Centrexion Therapeutics, J. Campbell Shareholder of: Centrexion Therapeutics, Employee of: Centrexion Therapeutics, K. Guedes Shareholder of: Centrexion Therapeutics, Employee of: Centrexion Therapeutics, R. Burges Shareholder of: Centrexion Therapeutics, Employee of: Centrexion Therapeutics, P. Hanson Shareholder of: Centrexion Therapeutics, Employee of: Centrexion Therapeutics

DOI: 10.1136/annrheumdis-2017-eular.5309 